REVIEW

\title{
Demystified... recombinant antibodies
}

\author{
K A Smith, P N Nelson, P Warren, S J Astley, P G Murray, J Greenman
}

J Clin Pathol 2004;57:912-917. doi: 10.1136/icp.2003.014407

Recombinant antibodies are important tools for biomedical research and are increasingly being used as clinical diagnostic/therapeutic reagents. In this article, a background to humanised antibodies is given, together with details of the generation of antibody fragments - for example, single chain Fv fragments. Phage antibody fragments are fast becoming popular and can be generated by simple established methods of affinity enrichment from libraries derived from immune cells. Phage display methodology can also be used for the affinity enrichment of existing antibody fragments to provide a reagent with a higher affinity. Here, phage antibodies are demystified to provide a greater understanding of the potential of these reagents and to engage clinicians and biomedical scientists alike to think about potential applications in pathology and clinical settings.

See end of article for authors' affiliations

\section{Correspondence to:} $\operatorname{Dr} K$ A Smith, Division of Cell and Molecular Medicine, Postgraduate Medical Institute, University of Hull, Cottingham Rd, Hull HU6 7RX, UK; k.a.smith@hull. ac.uk

Accepted for publication 7 January 2004 t n a previous demystified article, ${ }^{1}$ we explained the development and application of monoclonal antibodies (MAbs). These reagents, largely of mouse/rat origin, are valuable as research tools-for example, probes of macromolecules and cells within the biomedical sciences-and as clinical diagnostic reagents. However, in clinical treatment, there has been a requirement to "humanise" these antibodies to minimise undesired side effects that effectively limit their repetitive use in patients. This article continues on the theme of antibody reagents in highlighting different forms of humanised recombinant antibodies, but with a larger emphasis on recombinant phage antibodies. In essence, a recombinant phage antibody is a small protein made up of both heavy and light variable chain domains (Fvs) that are usually coupled by a flexible peptide linker. These products, when displayed on phage retain the ability to recognise and bind antigen or, more specifically, a structural determinant or epitope. Phage derived antibody fragments offer benefits over traditional antibodies, such as a small penetrable size and rapid production. Furthermore, the technology can remove the need for animals. For the present, MAbs (and their variants) will continue to be used as essential "work horse" reagents in the clinical setting, but in the future, phage antibodies may provide an alternative option for therapeutics and as reagents in pathology laboratories. ${ }^{3}$

\section{HUMANISED RECOMBINANT} ANTIBODIES

In recent years MAbs have become very important commercial reagents, and currently contribute to over $30 \%$ of biopharmaceuticals in development and production. To date, 10 different MAbs have achieved FDA approval, with others in phase III trials. ${ }^{4}$ The key to the successful use of MAbs as diagnostic or therapeutic tools relies on their extraordinarily high degree of directional binding, which guarantees excellent target localisation. Importantly, those reagents finding useful clinical applications have been subjected to considerable molecular modification. The result has been to achieve "designer" antibodies that are less immunogenic, smaller, of greater affinity, or carry active therapeutic or diagnostic ligands. These ligands may be radiolabels for imaging, or more complex molecules that are either direct toxins or enzymes that can convert inactive prodrugs into cytotoxic forms. Evidence of their potential use is highlighted by the fact that there are more than 70 MAbs at phase II testing or beyond. ${ }^{5}$

"In essence, a recombinant phage antibody is a small protein made up of both variable heavy and light chain domains that are usually coupled by a flexible peptide linker"

Although the use of immunotherapy for treatment of neoplastic disease became an extremely exciting prospect after the development of rodent MAbs, this optimism was soon dampened by the early disappointing results when using murine MAbs in the targeting of tumours. ${ }^{6}$ One major problem was the human anti-murine antibody response (HAMA) against the administered antibodies. Other problems included less effective antibody dependent cell mediated cytotoxicity, which is notably dependent on immunoglobulin isotype, and a shorter biological half life compared with human antibodies. ${ }^{7}$ Most of these problems have been circumvented by the humanisation of murine antibodies to render them much less immunogenic than their native forms. Of course, the safety of the product is always paramount, and none more so than the use of Palavizumab to treat children at 2 years of age or less for

Abbreviations: $C$, constant region; $C D R$, complementarity determining region; CEA, carcinoembryonic; Fab, fragment antigen binding; Fc, fragment crystallisable; $\mathrm{H}$, heavy chain; HAMA, human anti-murine antibody response; $L$, light chain; $M A b$, monoclonal antibody; scFv, single chain heavy and light chain variable regions; $V$, variable; VEGF, vascular endothelial growth factor 
respiratory tract infections with respiratory syncitial virus. ${ }^{8}$ Unfortunately, the satisfactory production of human hybridomas has proved difficult, with low fusion rates, poor cell stability after viral (for example, Epstein Barr virus) transformation/immortalisation, and issues over safety. Currently, the availability of a human HAT (hypoxanthine, aminopterin, and thymidine) sensitive myeloma cell line may rectify some of these problems. ${ }^{9}$ In essence, the goal of humanisation has been to alter a murine or rat antibody through molecular engineering so as to include human elements and effectively reduce its immunogenicity to an acceptable level. Since the advent of molecular biology tools, four approaches have been adopted.

(1) First generation (chimaeric) antibodies: rodent variable region genes are cloned into a mammalian expression system that contains human heavy and light chain constant region gene components. Of importance is that the Fc (fragment crystallisable region) is chosen to provide an isotype relevant to the desired biological function. This approach has ultimately provided a chimaeric antibody with a rodent Fab (fragment antigen binding) region and human Fc region. Problems of immunogenicity are still apparent and anti-allotype responses are minimised by using immunoglobulin with allotypes reflective of the ethnographic/population group.

(2) Second generation (hyperchimaeric) antibodies: this approach uses the complementarity determining regions (CDRs) of the original rodent antibody, which are grafted into the framework of a human antibody. The DNA encoding the three CDRs from both the heavy and light chains are used to generate an antibody that is more "human" (and therefore less immunogenic) compared with a first generation antibody.

(3) Hyperchimaerisation (veneering): this approach attempts to improve hyperchimaeric antibodies by modifying any framework or "scaffold" residues that are crucial to the antibody combining site. Allowances and modifications for respective consensus sequences may alleviate any mismatch of framework residues that could have a pronounced effect on antibody affinity. ${ }^{10}$

(4) Humanised bispecific antibodies: in this scenario, MAbs that recognise two entirely different epitopes may be used to generate a novel reagent with dual specificityfor example, the combination of anti-CD3 and the HER2 receptor antibody. ${ }^{11}$

The modification and humanisation of the antibody Campath (anti-CD52; Alemtuzemab) over the years provides a unique example of the above. Campath-1M (rat IgM), Campath-1G (rat IgG.2b), and Campath-1H (human IgG. $\gamma 1$ ) have been used to counteract transplant rejection and treat inflammatory and autoimmune diseases. In its final form, Alemtuzumab continues to find application in the treatment of leukaemias (for example, chronic lymphocytic leukaemia) and is currently being further refined by its combination with Rituximab, a chimaeric anti-CD20 MAb that can be used with or without chemotherapy. ${ }^{12}$ Current developments include the recent acceptance of Omalizumab, a humanised monoclonal antibody for the treatment of allergic asthma, although some concerns remain over its possible implication in the development of thrombocytopenia and clotting abnormalities, which has precluded its use in the treatment of allergic rhinitis. ${ }^{13}$ Therapeutic MAbs will continue to have a role in the slowing down or prevention of malignant processes-for example, anti-human papillomavirus antibody for cervical cancer and anti-vascular endothelial growth factor (VEGF)/anti-VEGF receptor antibody to inhibit the vascularisation and growth of small tumours. A further approach in reducing metasatic spread is to use a humanised MAb to inhibit stromal expansion in metastatic colorectal cancer by targeting the fibroblast activation protein. ${ }^{14}$

\section{RECOMBINANT PHAGE TECHNOLOGY}

Antibody fragments such as Fabs and Fvs (fig 1) have the same binding characteristics as the parent antibody, although they often have a reduced affinity. In general, such antibody fragments are extremely easy to produce in bacteria because they are rarely glycosylated, unlike the parent antibody. Fab fragments can be produced as heavy and light chains that are held together by interaction of the CL and CHl domains; however, production of $\mathrm{Fv}$ fragments in this way is not as effective because the VH and VL domains do not associate as efficiently. This problem led to the construction of single chain Fv fragments (scFvs), where the heavy and light chain $\mathrm{V}$ regions are linked by a short peptide. Antibody fragments, such as scFvs and Fabs, have been generated from many existing MAbs because these have similar binding characteristics to the parent antibody, but because of their smaller size they have greatly improved tissue penetration and clearance. ${ }^{15}$

"A major breakthrough was reported in 1990 by
McCafferty et al, who described the display of single
chain Fvs on the surface of filamentous bacteriophage"

A major breakthrough was reported in 1990 by McCafferty et al, who described the display of scFvs on the surface of filamentous bacteriophage. ${ }^{16}$ The development of this technique has led to large repertoires of heavy and light chain $\mathrm{V}$ regions being amplified by the polymerase chain reaction from a human or immunised animal, and used to construct scFvs that are displayed on the bacteriophage surface. Filamentous phage, such as $\mathrm{Ml3}, \mathrm{fl}$, and fd, are virus-like particles that are able to infect Escherichia coli and contain a single stranded DNA genome encoding its five coat proteins. Upon infection, the single stranded DNA is replicated and phage particles are assembled and secreted into culture media without lysis of the bacterial cell. Antibody fragment DNA can be spliced to the gene sequence for a phage coat protein, resulting in a phage surface expressed scFv fusion protein (fig 2).

There are five different phage coat proteins that can be used for this purpose. The pVIII coat protein is often used, but because it is present at approximately 2700 copies on the phage particle the affinity of isolated $\mathrm{scFv}$ fusion proteins is often too low to be useful; more often, the pIII coat protein, which is present at three to five copies/phage is used. Most often, the antibody fragment sequence is fused to the pIII DNA in a phagemid vector, which then requires a wild-type helper phage to generate fully fledged phage displaying the antibody fragment-pIII fusion protein. The use of phagemid vectors is preferable to cloning scFv directly into the phage genome, because phagemids can be introduced into bacteria at a much higher efficiency and allow the creation of very large $\left(>10^{10}\right.$ clones) antibody repertoires displayed on filamentous phage. Antibody repertoires (or libraries) are usually classified according to the source of the antibody fragments ${ }^{17}{ }^{18}$ :

(1) Immunised libraries: heavy and light chain $\mathrm{V}$ regions are isolated from the $\mathrm{B}$ cells of an immunised animal (usually extracted from the spleen) or hybridoma cells generated from such an animal or even immunised humans. ${ }^{19}$ However, these repertoires will contain scFvs that are biased towards the immunogen, based on the host's immune response. Many groups have used immunised libraries to generate scFv antibodies. ${ }^{20-22}$ 


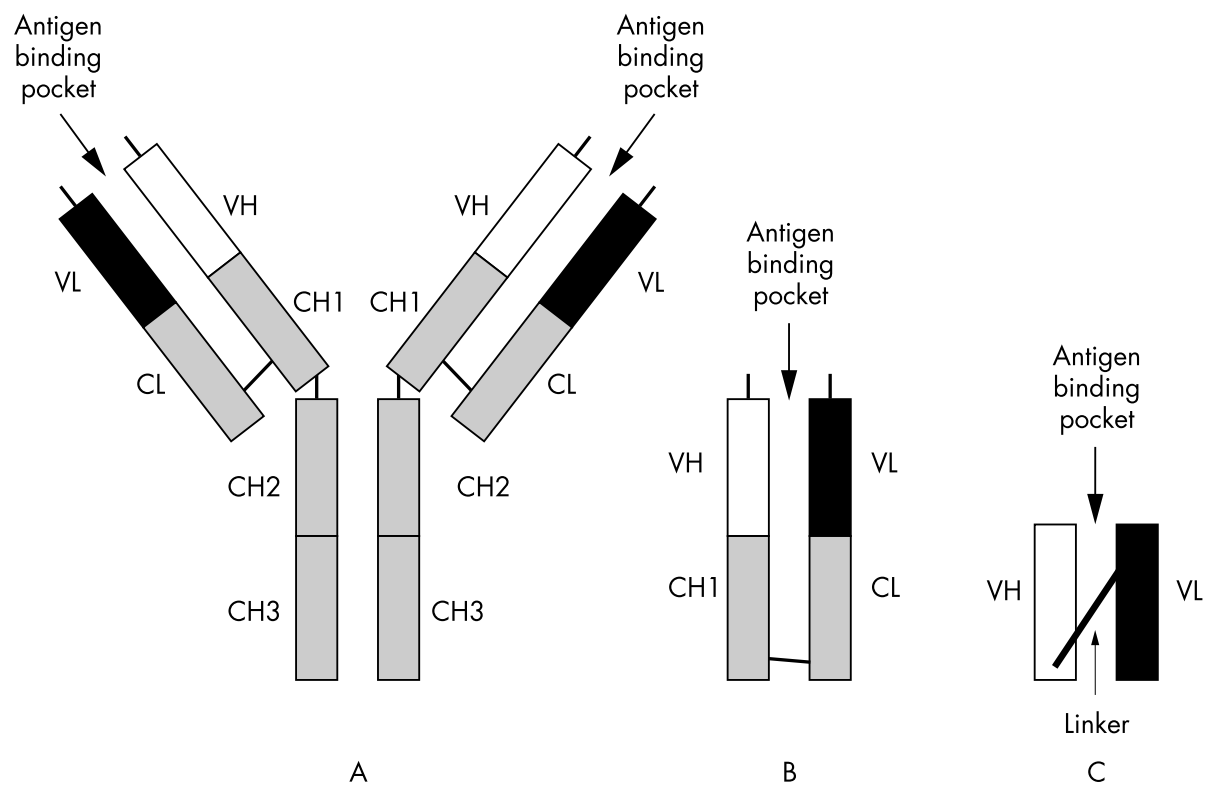

Figure 1 (A) Structure of a human antibody, (B) Fab fragment, and (C) a single chain Fv fragment-scFv. VH, variable region of heavy chain; VL, variable region of light chain; $\mathrm{CH}$, constant region of heavy chain; $\mathrm{CL}$, constant region of light chain.

This methodology has several advantages over traditional hybridoma technology; in particular, the ease of screening large numbers of clones, meaning that the selected scFv are often of higher affinity. Kits are now available, such as the "RPAS mouse scFv module" from Amersham Pharmacia Biotech (Little Chalfont, Buckinghamshire, UK), that can be used to generate scFv repertoires from mouse spleen or hybridoma cells.

(2) Semi-synthetic libraries: germline heavy and light chain $\mathrm{V}$ regions, cloned from human B cells, are assembled and synthetic randomisation is used to introduce additional diversity at the CDR3 region to increase the repertoire. This can generate a repertoire of many specificities (up to $10^{10}$ ), but the disadvantage is that not all of the randomly synthesised CDR3 regions will be suitable for antigen binding, reducing the functional size of the repertoire.

(3) Naïve libraries: heavy and light chain variable regions are amplified from the naïve IgM and IgG repertoire of a
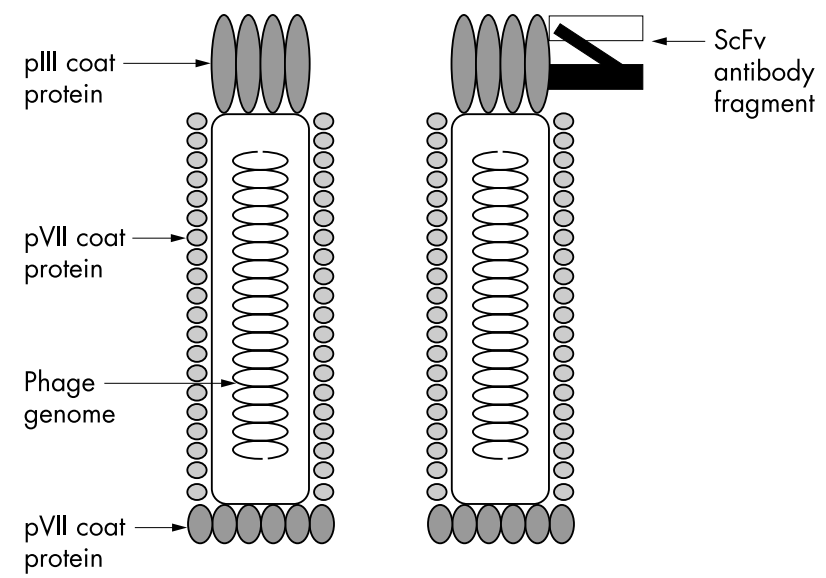

Figure 2 The structure of a phage particle (left) and the structure of a phage particle where a single chain heavy and light chain variable region fragment $(\mathrm{scFv})$ is expressed as a fusion to the plll coat protein (right). healthy human donor and randomly combined to produce scFv. After cloning into a phagemid vector and transformation into $E$ coli, a library is produced that expresses between $10^{7}$ and $10^{11}$ scFvs. The benefits of this type of library are that each scFv is fully human and each CDR3 region has a propensity for loop formation and binding because it is extracted from the human immune system. However, the affinity of the derived scFv can be low unless a very large repertoire is generated, as has been done by Vaughan et al, ${ }^{23}$ who generated very high affinity antibodies from a library of $1.4 \times 10^{10}$ scFvs.

All the repertoires described above can be used to select antibody fragments to particular antigens. In general, phage displaying scFvs that bind to a particular antigen can be isolated by simply "panning" against the target protein/ peptide/cell by multiple rounds of affinity selection (fig 3 ). In addition to the use of immunised libraries to provide an alternative way of generating mouse antibody fragments to an immunogen, naïve and semi-synthetic libraries that contain scFvs recognising an enormous range of molecules can be used when immunisation is not feasible-for example, when an antigen is in poor supply, non-immunogenic, or highly toxic. Antibody fragments can also be generated to novel antigens using phage technology, such as carbohydrate moieties on cell surfaces and tumour cell markers. Another benefit of $\mathrm{scFv}$ fragments is that if they are of human origin they are more amenable for use in treatment because a HAMA response is less likely to occur, although it is possible that human scFvs could still elicit an anti-idiotype response.

\section{APPLICATIONS}

Characterised phage antibodies can easily be used as laboratory reagents to replace conventional whole antibodies in applications such as flow cytometry or immunohistochemistry. Figure 4 shows an example of immunohistochemical staining in a colon adenoma using a phage displayed antibody specific to VEGF-A 165. If the selected scFv is to be purified for use in therapeutic applications, it is relatively easy to extract the DNA encoding the scFv fragment from the 


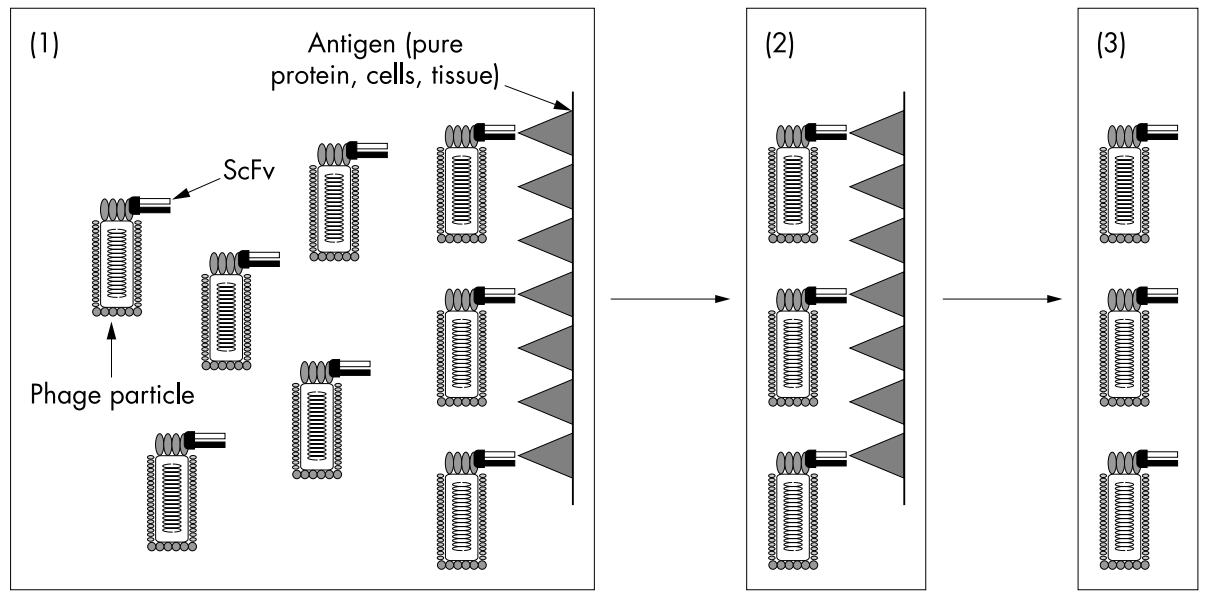

Figure 3 Selecting antibodies from phage libraries. (1) Phage are incubated with the antigen of interest-any phage that express a single chain heavy and light chain variable region fragment (scFv) that binds to the antigen. (2) Phage that express scFv fragments that do not bind to the antigen are washed away. (3) Phage that express scFv fragments that bind to the antigen are isolated, expanded, purified, and then used in further applications.

phagemid, and subclone into a more suitable expression vector.

A concern of using phage antibodies in diagnostics-for example, in immunocytochemistry or enzyme linked immunosorbent assay-has been the reliance on a single antigen binding site (as compared with two for native IgG). As a consequence, the affinity of the antibody-antigen interaction must be high to prevent loss during washing procedures. However, with technology such as plasmon resonance (for example, BIACore), which provides a measure of affinity, ${ }^{24}$ the strength of binding, and of course empirical observation in vitro, can readily offset any such unease.

Affinity maturation of an existing antibody can be undertaken such that the scFv binds with higher affinity than the original antibody. ${ }^{17}{ }^{18}$ Briefly, this is performed by generating a series of heavy and light chain variable regions that are based on the original antibody by error prone polymerase chain reaction, or the use of mutator $E$ coli strains, and then selecting scFvs against the original antigen. Such approaches have been used successfully to generate higher affinity scFv from the Ki4 monoclonal antibody that recognises CD $30,{ }^{25}$ the classic marker of Reed-Sternberg cells in Hodgkin

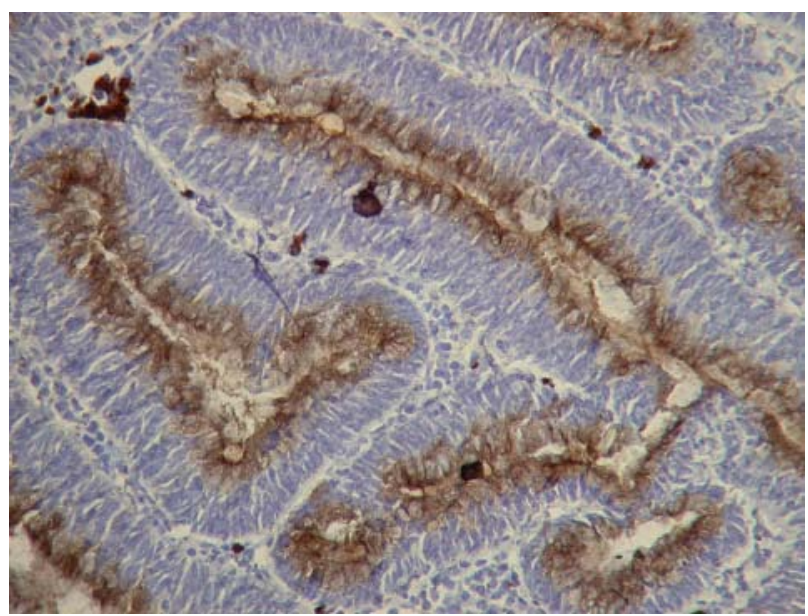

Figure 4 Immunohistochemical staining in a colon carcinoma using a phage displayed antibody specific to vascular endothelial growth factor 165 . Original magnification, $\times 40$. lymphoma. Similarly, phage antibodies to oestradiol have been enhanced using site directed mutagenesis. ${ }^{26}$

One of the strengths of phage antibody technology is the ability to "rescue hybridomas", where mRNA is extracted from the original hybridoma followed by reverse transcription and amplification of the light and heavy chains. An appropriate peptide linker is then coamplified with the heavy and light chains to provide an $\mathrm{scFv}$ gene for insertion into a suitable vector.

"Affinity maturation of an existing antibody can be undertaken such that the single chain heavy and light chain variable region fragment binds with higher affinity than the original antibody"

ScFvs are currently being used in many clinical trials for both diagnosis and treatment. ${ }^{4}$ Many of these are murine scFvs derived from a hybridoma, although there are now some fully human scFvs that have been derived from naïve or synthetic libraries. One of the most widely used scFvs, and the first to enter the clinic is MFE-23, which recognises the carcinoembryonic antigen (CEA or CD66e), a molecule that is highly expressed in gastrointestinal tumours. ${ }^{27} \mathrm{CEA}$ specific scFv fragments were generated from a phage antibody library produced from a mouse immunised with human CEA. MFE23 binds with high affinity to CEA $(\mathrm{kDa}=2.4 \mathrm{~nm})$ and has been used in various trials-for example, the conjugation of MFE-23 to ${ }^{123} \mathrm{I}$, for use as a cancer cell imaging tool, and to ${ }^{125} \mathrm{I}$, for use in radioimmunoguided surgery. Further work is ongoing to investigate the use of MFE-23 in antibody directed enzyme prodrug treatment. ${ }^{27}$

Overall, recombinant phage antibodies offer scope as research tools and in vaccine development. ${ }^{28}$ More recently, Watkins et al $(2003)^{29}$ have developed scFvs against thrombospondin that could prove invaluable in the study of sickle red blood cells. In the past few years, there has been an increase in the number of publications relating to and using phage technology in the synthesis of recombinant antibodies and antibody fragments; table 1 lists some selected examples of these. The applications of scFvs are varied and encompass a broad range of disciplines, such as the study of autoantibodies (construction of Fab fragments of annexin-XI), ${ }^{43}$ targeted gene therapy, and oncology. In addition, scFvs have been generated with specificity to foot and mouth virus. ${ }^{44}$ In the field of microbiology, phage antibodies (scFv5 and 
Table 1 Selected examples of phage antibodies with applications in clinical settings

\begin{tabular}{|c|c|c|c|}
\hline scFv target & Clinical use & Type of selection & Ref \\
\hline \multicolumn{4}{|c|}{ scFvs genetically engineered from existing antibodies } \\
\hline Novel tumour associated antigen & Tumour imaging (melanoma) & scFv of $\mathrm{H} 11$ murine monoclonal antibody & 30 \\
\hline Anti-idiotypic antibody of ACA 125 & Tumour targeting (ovarian) & scFv of murine antibody ACA 125 & 31 \\
\hline Tumour associated glycoprotein-72 & Tumour targeting (colon) & scFv of CC49 murine monoclonal antibody & 32 \\
\hline Platelet glycoprotein $1 \mathrm{~b} \alpha$ & Anti-thrombotic agent & $\mathrm{scFv}$ of SZ-2 murine monoclonal antibody & 33 \\
\hline \multicolumn{4}{|c|}{ Murine scFvs that have undergone affinity enrichment by phage display } \\
\hline HMW-MAA & Tumour targeting (melanoma) & Affinity enrichment of murine scFv & 34 \\
\hline CD30 & Tumour targeting (Hodgkin) & Affinity enrichment of $\mathrm{Ki} 4$ murine scFv & 25 \\
\hline EрCAM & Tumour targeting (colon) & $\begin{array}{l}\text { Affinity enrichment of the MOC- } 31 \text { murine } \\
\text { antibody }\end{array}$ & 35 \\
\hline $\begin{array}{l}\text { L1 } \\
\text { scFvs selected from immunised phage }\end{array}$ & Role of $\mathrm{L} 1$ in nervous system & Affinity enrichment of murine antibody & 36 \\
\hline CEA & Tumour targeting (colon) & $\begin{array}{l}\text { Selected from a CEA immunised mouse } \\
\text { hybridoma library }\end{array}$ & 20 \\
\hline EGFR & Tumour targeting (general) & $\begin{array}{l}\text { Selected from an EGFR immunised mouse } \\
\text { hybridoma library }\end{array}$ & 22 \\
\hline Pertussis toxin & $\begin{array}{l}\text { Neutralisation of pertussis } \\
\text { infection }\end{array}$ & $\begin{array}{l}\text { Selected from a library assembled from } \\
\text { patients recovering from pertussis infection }\end{array}$ & 37 \\
\hline p24 (HIV) & HIV diagnosis & $\begin{array}{l}\text { Selected from a viral lysate immunised } \\
\text { mouse hybridoma library }\end{array}$ & 38 \\
\hline \multicolumn{4}{|c|}{ Human scFvs selected from naïve phage libraries } \\
\hline CD55 & Tumour targeting (lung) & Naïve library selected on lung carcinoma cell line & 39 \\
\hline EpCAM & Tumour targeting (colon) & Naive library selected on colorectal cell line & 40 \\
\hline Fibronectin & Tumour targeting & Naive library selected on fibronectin fusion protein & 41 \\
\hline VEGF & Blocking angiogenesis & Naïve library selected on recombinant VEGF & 42 \\
\hline Thrombospondin-1 & Sickle RBC adhesion & Naïve library selected on thrombospondin-1 & 29 \\
\hline
\end{tabular}

scFv12) to Candida albicans have been developed that do not bind with related species, ${ }^{45}$ and phage antibodies have also been raised to pathogenic and non-pathogenic strains of acanthamoeba. ${ }^{46}$

\section{CONCLUSION}

The generation of recombinant antibody fragments using phage display libraries will probably provide a useful complement to traditional hybridoma technology, particularly in the analysis of the vast quantities of data generated from the human genome project. Many scFv versions of existing antibodies generated from immunised phage antibodies are already in clinical trials, but advances in construction and screening of naïve and semi-synthetic libraries mean that in the past few years a large number of fully human scFvs have been generated to a range of molecules. ${ }^{39} 4042$ Over the coming years, it is very probable that many of these human scFv fragments will enter clinical

\section{Take home messages}

- Recombinant antibodies are rapidly becoming more popular as therapeutic and clinical tools

- Many existing murine antibodies have been humanised by antibody engineering to improve their therapeutic properties

- Antibody fragments have some benefits over intact antibodies because of their smaller size and ease of production

- Antibody fragments, particularly single chain heavy and light variable regions, can be generated by phage display methodology

- This technology has been used to produce many different antibody fragments, many of which have applications in the fields of microbiology and cancer treatment and imaging trials, and it is anticipated that these will offer new opportunities to target tumour cells, diagnostically or therapeutically, or alternatively play a role in controlling autoimmune disease. In the quest for developing antibodies to specified target epitopes on a molecule, epitope mapping $^{47} 48$ and bioinformatic tools ${ }^{49}$ (which predict "hot spots" of antigenicity) could be used to pinpoint regions that may be highly unique (hence avoiding crossreactivity), accessible, and hydrophilic. After the peptide synthesis, the availability of a phage library can then be used to pan against a desired peptide to obtain an antibody of choice. Recently (Nelson PN, Smith KA, Greenman J, 2003, personal communication) two phage antibodies have been developed to the human endogenous retrovirus HERV-K $10^{50}$ using this approach, which may prove useful in the characterisation of HERV in disease. Evidently, this move towards generating antibodies (that is, picking antibodies of the shelf) will revolutionise the future manufacture of antibodies.

\section{Authors' affiliations}

K A Smith, J Greenman, Division of Cell and Molecular Medicine, Postgraduate Medical Institute, University of Hull, Cottingham Rd, Hull HU6 7RX, UK

P N Nelson, P Warren, S J Astley, Molecular Immunology Research Group, Research Institute in Healthcare Science, School of Applied Sciences, University of Wolverhampton, Wulfruna Street,

Wolverhampton WV1 1SB, UK

P G Murray, Department of Pathology, Division of Cancer Studies, The Medical School, University of Birmingham B15 2TT, UK

\section{REFERENCES}

1 Nelson PN, Reynolds GM, Waldron EE, et al. Demystified... Monoclonal antibodies. Mol Pathol 2000;53:111-17.

2 Nelson PN, Astley SJ, Warren P. Monoclonal antibodies: the generation and application of "tools of the trade" within biomedical science. In: Crocker J, Murray PG, eds. Molecular biology in cellular pathology. New York: John Wiley \& Sons Ltd, 2003:329-49.

3 Nabhan C, Dyer MJ, Rosen ST. Current status of monoclonal antibody therapy for chronic lymphocytic leukaemia. Oncology 2003;17:253-62.

4 Souriau C, Hudson PJ. Recombinant antibodies for cancer diagnosis. Expert Opin Biol Ther 2003;3:305-18. 
5 Stockwin L, Holmes S. The role of therapeutic antibodies in drug discovery. Biochem Soc Trans 2003;31:433-6.

6 Gavilondo JV, Larrick JW. Antibody engineering at the millennium. Biotechniques 2000;29:128-45.

7 Khazaeli MB, Conry RM, LoBunglio AF. Human immune response to monoclonal antibodies. J Immunother 1994;15:42-52.

8 Lacaze-Masmonteil T, Seidenberg J, Mitchell I, et al. Evaluation of the safety of palivizumab in the second season of exposure in young children at risk for syncitial respiratory virus infection. Drug Saf 2003;26:283-91.

9 Karpas A, Drumechuva A, Czepulkowski B. A human myeloma cell line suitable for the generation of human monoclonal antibodies. Proc Natl Acad Sci U S A 2001;98:1799-804.

10 Taylor G, Furze J, Tempest PR, et al. Humanised monoclonal antibody to respiratory syncitial virus. Lancet 1991;337:1411-12.

11 Shalaby M, Shepard H, Presta L, et al. Development of humanised bi-specific antibodies reactive with cytotoxic lymphocytes and tumour cells expressing HER2 oncogene. J Exp Med 1992;175:217-25.

12 Nabhan C, Dyer M, Rosen S. Current status of monoclonal antibody therapy for chronic lymphocytic leukaemia. Oncology (Huntingt) 2003;17:253-62; discussion 264, 267.

13 D'Amato G. Therapy of allergic bronchial asthma with omalizumab - an antiIgE monoclonal antibody. Expert Opin Biol Ther 2003;3:371-6.

14 Hofheinz R, Al-Batran S, Hartmann F, et al. Stromal antigen targeting by a humanised monoclonal antibody: an early phase II trial of Sibrotuzumab in patients with metastatic colorectal cancer. Onkologie 2003;26:44-8.

15 Colcher D, Pvlinkova G, Beresford G, et al. Pharmacokinetics and biodistribution of genetically engineered antibodies. Q J Nucl Med 1998;42:225-41

16 McCafferty J, Griffiths AD, Winter G, et al. Phage antibodies: filamentous phage displaying antibody variable domains. Nature 1990;348:552-4.

17 Hoogenboom HR, deBruine AP, Hufton SE, et al. Antibody phage display technology and its applications. Immunotechnology 1998;4:1-20.

18 Hoogenboom HR, Chames P. Natural and designer binding sites made by phage display technology. Immunol Today 2000;21:371-8.

19 Cai XH, Garen A. Anti-melanoma antibodies from melanoma patients immunized with genetically-modified autologous tumour-cells - selection of specific antibodies from single-chain fv fusion phage libraries. Proc Natl Acad Sci U S A 1995;92:6537-41.

20 Chester KA, Begent RHJ, Robson L, et al. Phage libraries for the generation of clinically useful antibodies. Lancet 1994;343:455-6.

21 Tordsson J, Lavasani S, Ohlsson L, et al. A3-a novel colon and pancreatic cancer reactive antibody from a primate phage library selected using intact tumor cells. Int J Cancer 2000;87:559-68.

22 Kettleborough CA, Ansell KH, Allen RW, et al. Isolation of tumor cell specific single chain Fv from immunised mice using phage antibody libraries and the reconstruction of whole antibodies from these fragments. Eur J Immunol 1994;24:952-8.

23 Vaughan TJ, Williams AJ, Pritchard K, et al. Human antibodies with subnanomolar affinities isolated from a large non-immunized phage display library. Nat Biotechnol 1996;14:309-14.

24 Nelson PN, Westwood OMR, Soltys A, et al. Characterisation of epitopes of pan-lgG/anti-G3m(u) and anti-Fc monoclonal antibodies. Immunol Lett 2003;88:77-83.

25 Klimka A, Barth S, Matthey B, et al. An anti-CD30 single chain Fv selected by phage display and fused to Pseudomonas exotoxin $\mathrm{A}(\mathrm{Ki}-4(\mathrm{scFv})-\mathrm{ETA})$ is a potent immunotoxin against a Hodgkin-derived cell line. Br J Cancer 1999:80:1214-22

26 Coulon S, Mappus E, Cuilleron CY, et al. Improving the specificity of an antiestradiol antibody by random mutagenesis and phage display. Dis Markers 2000; 16:33-5

27 Chester KA, Mayer A, Bhatia J, et al. Recombinant anti-carcinoembryonic antigen antibodies for targeting cancer. Cancer Chemother Pharmacol 2000;46:S8-12

28 Morimoto K, Schnell MJ, Pulmanausahakul R, et al. High level expression of a human rabies virus-neutralizing monoclonal antibody by a rhabdovirus-based vector. J Immunol Methods 2001;252:199-206.
29 Watkins NA, Du LM, Scott JP, et al. Single-chain antibody fragments derived from a human synthetic phage display library bind thrombospondin and inhibit cell adhesion. Blood 2003;102:718-24.

30 Reilly RM, Maiti PK, Kiarash R, et al. Rapid imaging of human melanoma xenografts using an scFv fragment of the human monoclonal antibody $\mathrm{H} 11$ labelled with In-111. Nucl Med Commun 2001;22:587-95.

31 Reinartz S, Wagner U, Giffels P, et al. Immunological properties of a single chain fragment of the anti-idiotypic antibody ACA125. Cancer Immunol Immunother 2000:49:186-92.

32 Pavlinkova G, Booth BJM, Batra SK, et al. Radioimmunotherapy of human colon cancer xenografts using a dimeric single-chain Fv antibody construct. Clin Cancer Res 1999;5:2613-19.

33 Dai K, Zhu H, Ruan C. Generation and characterization of recombinant single chain Fv antibody that recognizes platelet glycoprotein Ibalpha. Thromb Res 2003; 109:137-44.

34 Kang N, Hamilton S, Odili J, et al. In vivo targeting of malignant melanoma by (125)lodine- and (99 m)Technetium-labelled single chain Fv fragments against high molecular weight melanoma-associated antigen. Clin Cancer Res 2000;6:4921-31.

35 Roovers RC, van der Linden $E$, deBruine $A P$, et al. In vitro characterisation of a monovalent and bivalent form of a fully human anti-EpCAM phage antibody. Cancer Immunol Immunother 2001;50:51-9.

36 Dong L, Chen S, Bartsch U, et al. Generation of affinity matured scFv antibodies against mouse neural cell adhesion molecule L1 by phage display. Biochem Biophys Res Commun 2003;301:60-70.

37 Williamson P, Matthews R. Development of neutralising human recombinant antibodies to pertussis toxin. FEMS Immunol Med Microbiol 1999:23:313-19.

38 de Haard HJW, Kazemier B, Koolen MJM, et al. Selection of recombinant library-derived antibody fragments against p24 for human immunodeficiency virus type-1 diagnostics. Clin Diagn Lab Immunol 1998;5:636-44.

39 Ridgway JJB, Ng E, Kern JA, et al. Identification of a human anti-CD55 single chain Fv by subtractive panning of a phage library using tumor and non-tumor cell lines. Cancer Res 1999:59:2718-23.

40 Huls GA, Heijnen IAFM, Cuomo ME, et al. A recombinant, fully human monoclonal antibody with anti-tumor activity constructed from phage displayed antibody fragments. Nat Biotechnol 1999;17:276-81.

41 Carnemolla B, Neri D, Castelliani $P$, et al. Phage antibodies with pan species recognition of the oncofoetal angiogenesis marker fibronectin ED-B domain. Int J Cancer 1996;68:397-405.

42 Vitaliti A, Wittmer R, Steiner L, et al. Inhibition of tumor angiogenesis by single chain antibody directed against vascular endothelial growth factor. Cancer Res 2000:60:4311-14.

43 Farneas $L$, Ditzel HJ. Dissecting the cellular functions of annexin XI using recombinant human annexin $\mathrm{XI}$-specific autoantibodies cloned by phage display. J Biol Chem 2003 Jun 11. [Epub ahead of print].

44 ShengFeng $\mathrm{C}$, Ping $\mathrm{L}$, Tao $\mathrm{S}$, et al. Construction, expression, purification, refold and activity assay of a specific scFv fragment against foot and mouth disease virus. Vet Res Commun 2003;27:243-56.

45 Bliss JM, Sullivan MA, Malone J, et al. Differentiation of Candida albicans and Candida dubliniensis by using recombinant human antibody single-chain variable fragments specific for hyphae. J Clin Microbiol 2003;41:1152-60.

46 Khan NA, Greenman J, Topping KP, et al. Isolation of Acanthamoeba specific antibodies from a bacteriophage display library. J Clin Microbiol 2000;38:2374-7.

47 Nelson PN. Generating monoclonal antibody probes and techniques for characterizing and localising reactivity to antigenic determinants. In: Westwood OMR, Hay FC, eds. Epitope mapping: a practical approach. Oxford: Oxford University Press, 2001:100-20.

48 Spencer DIR, Robson L, Purdy D, et al. A strategy for mapping and neutralizing conformational immunogenic sites on protein therapeutics. Proteomics 2002;2:271-9.

49 Roden D, Ejtehadi HD, Rowland-Jones S, et al. Bioinformatic analysis of HERV-K10. Immunology 2001;104:112.

50 Nelson PN, Carnegie PR, Martin J, et al. Human endogenous retroviruses demystified. Mol Pathol 2003;53:11-18. 